\title{
Qualidade microbiológica de Caldo de cana-de-açúcar comercializado em feira livre de União dos Palmares, Alagoas
}

\section{Microbiological quality of sugarcane juice marketed in a free fair in União dos Palmares, Alagoas, Brazil}

\author{
Clara Beatriz Ataíde ${ }^{1}$, Sybelle Geórgia Mesquita da Silva², João Manoel da Silva², Jéssica Raimundo da \\ Rocha ${ }^{3}$, Jéssica Marcy Silva Melo Santos ${ }^{4}$, Tania Marta Carvalho dos Santos ${ }^{5}$
}

1Técnica em Agropecuária, Laboratório de Microbiologia Agrícola, Centro de Ciências Agrárias, Universidade Federal de Alagoas, e-mail: beatrizclara937@gmail.com; 2Rede Nordeste de Biotecnologia, Instituto de Química e Biotecnologia, Universidade Federal de Alagoas, e-mail: belle mesquita21@hotmail.com; joao.manoel@iqb.ufal.br; 3Programa de Pós-graduação em Química, Instituto de Química e Biotecnologia, Universidade Federal de Alagoas, e-mail: jessica-roch@hotmail.com; ${ }^{4}$ Engenheira Agrônoma, Departamento de Engenharia Agronômica, Universidade Federal de Sergipe, e-mail: marcymeloo@gmail.com; ${ }^{4}$ Professora Titular, Laboratório de Microbiologia Agrícola, Centro de Ciências Agrárias, Universidade Federal de Alagoas, e-mail: $\underline{\text { tmcs@ceca.ufal.br. }}$

\section{NOT A \\ C I E N T Í F I C A}

Recebido: 15/12/2019

Aprovado: 23/12/2019

\section{Palavras-chave:}

Bebida in natura

Segurança alimentar

Coliformes

Protozoários
Key words:

Drink in natura

Food Security

Coliforms

Protozoa

\section{R E S U M O}

O objetivo deste trabalho foi avaliar a qualidade microbiológica de amostras de caldo-de-cana de açúcar comercializados em feira livre no Estado de Alagoas. Sete amostras de caldos de cana-de-açúcar comercializados informalmente foram coletadas durante intervalos de quinze dias e levadas ao laboratório para as devidas análises. As amostras coletadas assepticamente foram diluídas em solução salina peptonada $0,1 \%$, onde $25 \mathrm{~mL}$ de cada amostra foi diluída em $225 \mathrm{~mL}$ desta solução e inoculadas em tubos de ensaio contendo meio Lauryl Sulfato Triptose e um tubo de Durham invertido para os testes presuntivos e, posteriormente, as amostras que formaram gás foram transferidas para tubos contendo meio E.C. e Verde Brilhante para testes de coliformes totais e termotolerantes, respectivamente. As leveduras foram analisadas por meio de inoculação em meio BDA e visualização microscópica. A detecção de protozoários foi feita através de armadilhas confeccionadas em tubo PVC em meio Agar-água. A sujidade foi analisada por meio de filtração e observação microscópica. Todas as amostras apresentaram coliformes totais e termotolerantes com contagem máxima de $>2400 \mathrm{NMP} / \mathrm{mL}$. A contagem de leveduras mostrou $8 \times 10^{-6}$ UFC. Dois caldos de cana-de-açúcar na primeira coleta apresentaram protozoários. E nenhum apresentou de sujidades. Diante dos dados, constata-se que os caldos de cana-de-açúcar estão fora dos padrões estabelecidos para com alimentos in natura.

\section{A B S T R A C T}

The objective of this work was to evaluate the microbiological quality of samples of sugarcane broth marketed in a fair in the State of Alagoas. Seven samples of informally traded sugarcane broth were collected at intervals of fifteen days and taken to the laboratory for analysis. The aseptically collected samples were diluted in $0.1 \%$ peptone saline solution, where $25 \mathrm{~mL}$ of each sample was diluted in $225 \mathrm{~mL}$ of this solution and inoculated into test tubes containing Lauryl Sulfate Triptose (LST) medium and an inverted Durham tube for the Presumptive tests and, subsequently, samples that formed gas were transferred to tubes containing EC medium and Brilliant Green for tests of total and thermotolerant coliforms, respectively. Yeasts were analyzed by means of inoculation in PDA medium and microscopic visualization. The detection of protozoa was done through traps made in PVC tube in Agar-water medium. The soil was analyzed by means of filtration and microscopic observation. All samples had total and thermotolerant coliforms with a maximum count of $>2400 \mathrm{MPN} / \mathrm{mL}$. The yeast count showed $8 \times 10^{-6}$ UFC. Of the total of 21 samples, only two in the first collection showed protozoa. None of the samples showed dirt.

\section{Revista Verde}

ISSN 1981-8203

Pombal, Paraíba, Brasil v. 14, n.5, Edição Especial, p.650-653, 2019 doi: 10.18378/rvads.v14i5.7603 


\section{INTRODUÇÃO}

O contexto histórico do Brasil coloca a cultura da a canade-açúcar como um dos principais produtos agrícolas de importância econômica para o país, sendo cultivada desde a época da colonização. Dada a sua importância, a partir do seu processo de industrialização obtêm-se vários produtos e subprodutos, os quais possuem suas devidas importâncias na cadeia produtiva.

O potencial de produção e o papel fundamental da canade-açúcar e de seus subprodutos - açúcar, etanol, aguardente, rapadura e energia elétrica, entre outros, tanto na agricultura quanto na indústria, fazem dessa cultura uma das mais importantes atividades da agroindústria nacional (BRYAN et al., 1998).

O caldo de cana-de-açúcar é um dos muitos alimentos comercializados por ambulantes e seu consumo como refresco é um costume antigo, mas que vem crescendo a cada ano, particularmente nas épocas mais quentes (JAY, 2005).

Por ser considerado um produto altamente nutritivo, de sabor agradável e barato, é comercializado nas ruas por vendedores ambulantes, que possuem moendas para extração. A maioria desses vendedores não possui instalações compatíveis, assim como instrução adequada, que permita aos consumidores obtenção do produto em condições higiênicosanitárias apropriadas (PRATI et al., 2005).

As precárias condições higiênico-sanitárias do local, aliadas à falta de treinamento e conhecimento dos vendedores sobre manipulação de alimentos, podem representar riscos à saúde da população, devido ao fato dos alimentos poderem ser facilmente contaminados por micro-organismos (SANTOS, 2011).

Considerando isso, a Vigilância Sanitária elaborou um Regulamento Técnico de Procedimentos Higiênico-Sanitários para Manipulação de Alimentos e Bebidas Preparados com Vegetais com objetivo de estabelecer procedimentos higiênico-sanitários para preparo, acondicionamento, armazenamento, transporte, distribuição e comercialização de alimentos e bebidas preparados com vegetais, com a finalidade de prevenir doenças de origem alimentar (ANVISA, 2005).

Diante do exposto objetivou-se por meio deste trabalho avaliar a qualidade microbiológica de amostras de caldo de cana-de-açúcar comercializados em diversos pontos do Município de União dos Palmares, Alagoas, considerando-se o fato que esta cidade foi durante mais de um século formada, em sua maioria, pela monocultura da cana-de-açúcar, fazendo com que o município se tornasse unicamente dependente desta cultura (SILVA et al., 2016).

\section{MATERIAL E MÉTODOS}

Foram coletadas sete amostras de caldos de cana-deaçúcar comercializados informalmente por ambulantes em feira-livre no município de União dos Palmares, Alagoas, onde cada amostra foi coletada em diferentes ambulantes. Realizaram-se três coletas com intervalos de quinze dias, as quais foram acondicionadas em frascos estéreis, identificadas e encaminhadas ao Laboratório de Microbiologia Geral da Universidade Federal de Alagoas para posteriores análises. A coleta quinzenal proporciona caracterizar a ocorrência dos micro-organismos nas amostras.
As amostras coletadas assepticamente foram diluídas em solução salina peptonada a $0,1 \%$. Assim, $25 \mathrm{~mL}$ da amostra de cada caldo-de-cana foi diluída em $225 \mathrm{~mL}$ de água peptonada esterilizada. A partir dessa diluição foram feitas diluições seriadas decimais, onde $1 \mathrm{~mL}$ da primeira diluição foi transferido para um frasco contendo $9 \mathrm{~mL}$ de água peptonada a $0,1 \%$. As demais diluições foram feitas de igual modo até atingir diluição $10^{-5}$. A partir destas diluições, foram realizados testes para presença de coliformes totais, termotolerantes e leveduras.

Para o teste de coliformes, utilizaram-se as três primeiras diluições $\left(10^{-1}\right.$ a $\left.10^{-3}\right)$, onde foram inoculadas em tubo de ensaio contendo $10 \mathrm{~mL}$ de meio de cultura LST (Lauryl Sulfato) e um tubo de Durhan invertido e incubado por $48 \mathrm{~h}$. Após este período, foi verificado se houve formação de bolhas dentro do tubo de Durhan, sendo indicativo da presença de tais micro-organismos nas amostras. Das amostras que apresentaram formação de gás, foi transferido $1 \mathrm{~mL}$ para tubos de ensaio contendo $10 \mathrm{~mL}$ do meio de cultura Verde Brilhante e EC, durante 48 e $24 \mathrm{~h}$ a $35^{\circ} \mathrm{C}$, respectivamente, onde também foi observada a produção de gás.

Para leveduras foi utilizado o meio B.D.A. (Batata Dextrose Agar) modificado com adição de Rosa Bengala, no qual foi inoculado $1 \mathrm{~mL}$ da diluição $10^{-5}$ em placas de Petri e espalhada por toda a superfície do meio com auxílio de uma alça de Drigalsk, e observado o crescimento de leveduras após cinco dias e visualizado em microscópio óptico. Os resultados foram expressos em Unidade Formadoras de Colônias/mL (UFC/mL).

Os protozoários foram observados em microscopia após inoculação em ágar-água. Onde, em placas de Petri contendo meio de cultura Agar-água, foram posicionados poços confeccionados com tubos de PVC esterilizados contendo uma solução bacteriana Gram Negativa, servindo de armadilha para a captura dos protozoários, onde foi adicionado $1 \mathrm{~mL}$ do caldo de cana ausente de diluição e verificada a presença dois dias após inoculação.

A análise de sujidade foi realizada apor meio de filtração do caldo em papel filtro e observação microscópica, onde foi constatada ausência ou presença de sujidades.

Os dados obtidos foram submetidos às análises de contagem de número mais provável $(\mathrm{NMP} / \mathrm{mL})$ e Unidades Formadoras de Colônia (UFC/mL)_como descrito por Jay (2005).

\section{RESULTADOS E DISCUSSÃO}

Todos os caldos de cana-de-açúcar apresentaram coliformes totais e termotolerantes, com contagem máxima de $>2400 \mathrm{NMP} / \mathrm{mL}$ e mínima de $9,3 \mathrm{NMP} / \mathrm{mL}$ para coliformes totais a $35^{\circ} \mathrm{C}$ e máxima de $>2400 \mathrm{NMP} / \mathrm{mL}$, máxima de $>2400$ $\mathrm{NMP} / \mathrm{mL}$ e mínima de $1,5 \mathrm{NMP} / \mathrm{mL}$ para coliformes termotolerantes.

Na primeira coleta, uma contagem de $8 \times 10^{6}$ UFC foram encontradas para leveduras, resultado superior à terceira amostra, com $1,67 \times 10^{5}$ UFC. Somente em dois caldos de cana foram constatadas a presença de protozoários na primeira coleta. Além da contagem, as leveduras encontradas por meio do isolamento em meio BDA foram visualizadas em microscópio para confirmação de sua presença. Nenhum caldo de cana apresentou sujidades (Tabela 1). 
A presença de coliformes em grande quantidade caracteriza um risco quanto à má higienização dos utensílios e manipulação inadequada do alimento. De forma geral, os comerciantes armazenam as canas-de-açúcar diretamente no chão e/ou ao ar livre, prática irregular conforme estabelecido pela RDC 218. Além disso, a maioria dos manipuladores não emprega nenhuma medida de controle microbiano à cana-deaçúcar antes de moê-la, procedendo apenas a raspagem para remoção da casca, onde também, verifica-se que os mesmos manipulam dinheiro e o produto alimentar sem higienização das mãos ou utilização de luvas.

Tabela 1. Análises microbiológicas e microscópicas dos caldos de cana comercializados por ambulantes na feira livre na Cidade de União dos Palmares, Alagoas.

\begin{tabular}{|c|c|c|c|c|c|c|}
\hline \multirow{2}{*}{ Coleta } & \multirow{2}{*}{ Amostra } & \multicolumn{2}{|c|}{ Coliformes (NMP) } & \multirow[t]{2}{*}{ Levduras (UFC) } & \multirow[t]{2}{*}{ Protozoários } & \multirow[t]{2}{*}{ Sujidades } \\
\hline & & $35^{\circ} \mathrm{C}$ & $45^{\circ} \mathrm{C}$ & & & \\
\hline \multirow{7}{*}{1} & 1 & $>2400$ & $>2400$ & $2,0 \times 10^{6}$ & - & - \\
\hline & 2 & $>2400$ & $>2400$ & - & - & - \\
\hline & 3 & $>2400$ & $>2400$ & $1,0 \times 10^{7}$ & + & - \\
\hline & 4 & $>2400$ & $>2400$ & $1,5 \times 10^{6}$ & - & - \\
\hline & 5 & $>2400$ & $>2400$ & $1,9 \times 10^{6}$ & - & - \\
\hline & 6 & $>2400$ & $>2400$ & $1,0 \times 10^{7}$ & - & - \\
\hline & 7 & 120 & $>2400$ & $1,0 \times 10^{7}$ & + & - \\
\hline \multirow{7}{*}{2} & 1 & $>2400$ & $>2400$ & $5,6 \times 10^{6}$ & - & - \\
\hline & 2 & $>2400$ & $>2400$ & $3,6 \times 10^{6}$ & - & - \\
\hline & 3 & $>2400$ & $>2400$ & $4,9 \times 10^{6}$ & - & - \\
\hline & 4 & $>2400$ & $>2400$ & $4,5 \times 10^{6}$ & - & - \\
\hline & 5 & $>2400$ & $>2400$ & $3,4 \times 10^{4}$ & - & - \\
\hline & 6 & $>2400$ & $>2400$ & $1,0 \times 10^{6}$ & - & - \\
\hline & 7 & $>2400$ & $>2400$ & $3,9 \times 10^{4}$ & - & - \\
\hline \multirow{7}{*}{3} & 1 & $>2400$ & 1,5 & - & - & - \\
\hline & 2 & $>2400$ & $>2400$ & - & - & - \\
\hline & 3 & $>2400$ & $>2400$ & - & - & - \\
\hline & 4 & 9,3 & $>2400$ & - & - & - \\
\hline & 5 & 9,3 & $>2400$ & $1,6 \times 10^{5}$ & - & - \\
\hline & 6 & 1100 & $>2400$ & - & - & - \\
\hline & 7 & $>2400$ & 1,9 & - & - & - \\
\hline
\end{tabular}

Números de coliformes totais podem estar associados a estas más práticas de higienização e localização dos pontos de venda (CARVALHO; MAGALHÃES, 2007). Neste aspecto, uma saída que demonstra eficiência para os manipuladores de alimentos é o uso de antissépticos na higienização das mãos (ALMEIDA et al., 1995) bem como a utilização de luvas para que se evite o contato direto com o produto, além de adotar práticas higiênicas para armazenamento da cana antes do processo de moagem e comercialização.

Além da ausência de práticas higiênicas na manipulação da cana antes do processo de moagem, nota-se também a deficiente forma de armazenamento pré-venda do produto, onde todos os ambulantes armazenavam-na no chão, forrado apenas por lona ou em caixas de madeira, favorecendo o contato com o ambiente contaminado, além de proporcionar que pequenos insetos sejam atraídos, devido à presença de açúcares, sendo mais uma forma de contaminação do produto.

Embora a legislação vigente no Brasil não estabeleça padrões microbiológicos para bolores e leveduras, a presença destes micro-organismos pode indicar deterioração do produto a partir de contagens de $10^{-3}$, uma vez que estes organismos são capazes de produzir enzimas que deterioram e comprometem não só o produto físico, como também seu aroma e sabor, apesar de a cana-de-açúcar ser susceptível à colonização por leveduras, o aumento da quantidade de células pode estar associado à manipulação, armazenamento do produto, elevadas temperaturas do ambiente favorecendo o processo de fermentação ainda antes da moagem, ou mesmo por ser um produto vegetal cuja colheita tenha sido feita há alguns dias antes de sua comercialização, onde estes micro-organismos podem se desenvolver e multiplicar por ser um ambiente favorável.
Embora houvesse presença de protozoários em dois caldos de cana da primeira coleta, isto pode ser dado devido à má higienização e manipulação das máquinas, bem como uma possível presença de insetos vetores de tais micro-organismos que, por conta da ausência de observação da sanidade do material vegetal a ser comercializado, pode haver sua transmissão no local de venda, ou mesmo em seu armazenamento pré-venda.

Além destas condições, vale ressaltar que, ainda em campo, pode haver a presença de tais insetos, que por estarem presentes no colmo, e não havendo observação de sua presença, ser uma forma de passarem despercebidos pela moenda, além destes poderem ser micro-organismos ainda provenientes não somente de insetos vetores.

Entretanto, é preciso uma maior atenção quanto a este dado, uma vez que tem sido relatada, em várias regiões do país, a presença de protozoários patogênicos em bebidas in natura comercializadas informalmente ou absentes de processamento e/ou higienização.

Uma alternativa para melhoria da qualidade microbiológica de bebidas in natura comercializadas formal ou informalmente é a intervenção dos órgãos responsáveis ou uma intervenção educativa, como forma de orientação aos comerciantes para melhor manejo e armazenamento do produto. Além de fornecer informações acerca da importância das boas práticas de fabricação (BPF) quanto à necessidade de tal para se evitar a infecção alimentar por meio de alimentos contaminados por micro-organismos, bem como conferir conhecimento básico sobre a importância dos microorganismos patogênicos associados à infecção alimentar. 


\section{CONCLUSÃO}

O caldo de cana-de-açúcar comercializado em feira livre de União dos Palmares não está dentro dos padrões estabelecidos pela Vigilância Sanitária, necessitando de maior fiscalização, garantido a segurança alimentar dos consumidores.

\section{REFERÊNCIAS}

ALMEIDA, R. C. C.; KUAYE, A. Y.; SERRANO, A. M.; ALMEIDA, P. F. Avaliação e controle de qualidade microbiológica de mãos de manipuladores de alimentos. Revista de Saúde Pública, v.29, n.4, p.290-294, 1995. $\underline{10.1590 / \mathrm{S} 0034-89101995000400006}$

ANVISA. Agência Nacional de Vigilância Sanitária. Resolução - RDC nº. 218, 29 de Julho de 2005. Regulamento Técnico de Procedimentos Higiênico-sanitários para manipulação de alimentos e bebidas preparadas com vegetal, Brasília-DF. . 2005.

BRYAN, F. L.; MICHANIE, S. C.; ALVAREZ, P. Critical control points of street-vended foods in the Dominican Republic. Journal of Food Protection, v.51, v.5, p.373-383, 1998. 10.4315/0362-028X-51.5.373

CARVALHO, L. R.; MAGALHÃES, J. T. Avaliação da qualidade micobiológca de caldos de cana comercializados no centro de Itabuna-BA e práticas de produção e higiene de seus manipuladores. Revista Baiana de Saúde Pública, v.31, n.2, p.238-245, 2007.

JAY, J. M. Microbiologia de alimentos. 6 ed. Porto Alegre, Rio Grande do Sul: Artmed, 2005.

PRATI, P.; MORETTI, R. H.; CARDELLO, H. M. A. B. Elaboração de bebida composta por mistura de garapa parcialmente clarificada-estabilizada e sucos de frutas ácidas. Ciência e Tecnologia de Alimentos, v.25, n.1, p.147-152, 2005. $\underline{10.1590 / \mathrm{S} 0101-20612005000100024}$

SANTOS, S. S. O Cultivo da Cana-de-açúcar no Estado de Alagoas: uma análise comparativa dos efeitos de mecanização no estado de São Paulo. 2011. 104F. (Dissertação de Mestrado). Universidade de Brasília, Brasil.

SILVA, E. L.; SILVA, A. J.; SILVA, C. O. Do Auge à Decadência: Um Estudo dos Impactos Socioeconômicos da Falência da Usina Laginha para União dos Palmares-AL. In: Anais do $4^{\circ}$ GeoAlagoas - Simpósio sobre as geotecnologias e geoinformação no Estado de Alagoas, Alagoas, Brasil, 6 October 2016 (pp. 14). Maceió, AL: Seplag. 